\title{
Educación y Democracia
}

Education and Democracy

\author{
Juana Sánchez-Gey Venegas \\ Universidad Autónoma de Madrid \\ juana.sanchez-gey@uam.es
}

DOI: https://doi.org/10.15366/bp2020.25.003

Bajo Palabra. II Época. No25. Pgs: 65-76 


\section{Resumen}

Educación y democracia son dos concepciones nucleares e integradoras en el pensamiento de María Zambrano. Al mismo tiempo ambas se entrelazan. La razón poética se hace razón mediadora cuando la filósofa reflexiona sobre la educción, de este modo educar consiste en formar a la persona en su contexto histórico y ciudadano. Si la razón poética propone una mirada sobre el mundo, el ritmo de esta mirada es la razón mediadora y demócrata.

Palabras clave: Educación, democracia, ciudadanía, razón y razón mediadora.

\section{Abstract}

Education and democracy are two nuclear and integrating concepts in Maria Zambrano's thinking. Both are intertwined. Poetic reason becomes mediating reason when our philosopher reflects on education, so that education becomes a way of forming people in a historical and social context. If the proposal of the poetic reason is a concrete way of looking at the world, it's rhythm is mediating and democratic reason.

Keywords: Education, democracy, citizenship, poetic reason, mediating reason. 


\section{Introducción}

Educación y Democracia es una relación propia en el pensamiento de María Zambrano, para centrarnos en ella conviene situarse en el núcleo fundamental de su pensamiento, esto es, en la razón poética. Mas, la razón poética se puede decir de muchas maneras. Así podríamos denominarla razón ética cuando trata temas referentes a la política o razón misericordiosa en su reflexión acerca de lo sagrado y, al referirnos a la educación, entonces adquiere el nombre de razón mediadora. En la Nota a la edición de 1987 de Hacia un saber sobre el alma, María Zambrano dice: "Aparecen aquí, en su germinación, esas dos formas de razón -la mediadora y la poética- que han guiado todo mi filosofar". ${ }^{1}$

Quiere decirse que la razón poética y la razón mediadora son formas de visión integradoras, pues aquélla es mediadora o, dicho de otro modo, ésta es poética. Esta es la fuerza de la aportación de María a la historia de la filosofía, una reflexión que une vida y pensamiento y que tiene como centro a la persona. Pues la filosofía busca comprender la vida, como decía su maestro, y especialmente, el sentido de la condición humana a la cual sólo puede accederse desde la mediación. La mediación es un concepto relacional que aúna diversas realidades, lo originario y lo originado, la teoría y la práctica, el sujeto y el objeto, etc. De este modo, si la razón poética procura una nueva mirada sobre el mundo, más concreta, más cotidiana y más completa y, de esta forma, da sentido a la crisis vital de la persona, podemos ańadir que la razón mediadora es el ritmo o el modo de acercamiento de esa mirada.

No es posible desde hace ya largo tiempo que la cultura de Occidente se encuentre, en medio de tantos espectadores, en una honda crisis. No es posible tampoco desconocer desde hace algún tiempo que esta crisis sea la de la mediación en todas sus formas. Son ellos, en gran parte mas en grado eminente, los mediadores mismos, quienes en forma cada vez más clara lo exponen, lo publican ${ }^{2}$.

Mediación es, pues, lo originario que en la tarea educativa consiste en la forma de acercarse y transformar la vida humana a fin de que alcance su plenitud. La

\footnotetext{
1 Zambrano, M., Hacia un saber sobre el alma, Madrid, Alianza Editorial, 1987, p. 9.

2 Zambrano, M., El pensamiento vivo de Séneca, Madrid, Alianza Editorial, 1987, p. 115.
} 
educación proporciona la mediación necesaria para que el ser humano sea completo, personal y socialmente. Por ello, la sociedad ha de estructurarse de modo que llegue a ser democrática, pues la democracia requiere el ejercicio de la libertad así como el desarrollo personal: "Se trata, pues, de que la sociedad sea la adecuada a la persona humana; su espacio adecuado y no su lugar de tortura" ${ }^{\text {. En Persona }}$ y Democracia afronta el hundimiento de la "Cultura de Occidente" y promueve esta forma de concretar a la persona como ser dotado de conciencia, capaz de llevar a cabo la humanización de la historia, así frente a una historia sacrificial, que es la que hasta ahora se ha desarrollado, se ha de promover una mediación de la cultura:

El único modo de evitar que tal hundimiento se produzca es hacer extensiva la conciencia histórica, al par que se abre cauce a una sociedad digna de esta conciencia y de la persona humana de donde brota. Es decir, en traspasar un dintel jamás traspasado en la vida colectiva, en disponerse de verdad a crear una sociedad humanizada y que la historia no se comporte como una antigua Deidad que exige inagotable sacrificio. ${ }^{4}$

Además de las referencias explícitas a la mediación en la Nota a la edición de Hacia un saber sobre el alma de 1987, existen otros muchos textos en los que desarrolla esta razón mediadora, especialmente en El pensamiento vivo de Séneca (1944) y en sus artículos: La vocación de Maestro y La Mediación del Maestro, publicados en los años sesenta. Zambrano defiende que la mediación tiene en cuenta a la persona para descubrirle la realidad y posibilitarle el desarrollo moral.

\section{El pensamiento vivo de Séneca}

ESTA OBRA QUE PUbLICA EN 1944, por encargo de Joaquín Xirau, nace de un proyecto de dar a conocer a filósofos espańoles desde el exilio. En el reparto que Xirau propone, le toca a María Zambrano escribir sobre Séneca, a quien admira. Y así dice: "Su misterio y su seducción provienen de que, sin duda, nos proponen algo, algo de lo que querríamos librarnos, alguna solución para nuestra vida que querríamos evitar, algún camino que no acabamos apenas de querer recorrer". ${ }^{5}$

La mediación surge de la necesidad de tener referencias, como afirma Hanna Arendt, pues el ser humano requiere "medirse ante alguien", se necesitan modelos

\footnotetext{
3 Zambrano, M., Persona y Democracia, Barcelona, Anthropos, 1992, p. 136.

4 Zambrano, M., Persona y democracia, op. cit., p. 12.

5 Zambrano, M., El pensamiento vivo de Séneca, op. cit., p. 25.
} 
que sean referentes y acompañantes: Séneca es un mediador, un padre o modelo de la tradición cultural a la que se pertenece. De este modo, la razón poética se hace así dulcificadora frente a la razón violenta. Por ello dice de Séneca: "Es propiamente un mediador, por lo pronto, entre la vida y el pensamiento, entre ese alto logos establecido por la filosofía griega como principio de todas las cosas, y la vida humilde y menesterosa". ${ }^{6}$

La razón mediadora supone siempre un conocimiento experiencial que une los fundamentos y los propios acontecimientos. Así, la filosofía guía y orienta toda la vida humana, la transforma y la realiza. Es ajena a la soberbia y se baja para compartir sueños de convivencia que alejen los individualismos devoradores. El racionalismo impidió la vivencia de una razón mediadora, que se hunde en el amor y conoce las entrañas o el sentir originario. Los racionalismos suponen violencia: "Toda razón ha de ser mediadora entre la nada y el ser, entre la soberbia de la vida y su acabamiento, su humillación" 7 :

Séneca es uno de los sabios mediadores que, abandonando el recinto de la pura sabiduría, tiende hacia el hombre, hacia el hombre de la calle de toda clase y condición, una mirada misericordiosa y se dispone a darle, no ya lo que sabe, sino lo que él necesita ${ }^{8}$.

De este modo, la razón mediadora es razón democrática porque tiende la mano a la realidad más concreta y cotidiana, al hombre de la calle, al que vive y sueńa en circunstancias concretas.

\section{La vocación del maestro}

El maestro es el MEdiAdor, o mejor aún, Zambrano no concibe esta condición sino desde la mediación. Pues el maestro no se sitúa en ningún saber absoluto y mucho menos, desde una razón encerrada en sí misma, porque su tarea es acompañar a la persona para que alcance sus sueńos: "Porque toda persona es ante todo una promesa. Una promesa de realización creadora"

Esta vocación hondamente sentida va acompañada siempre de una exigencia pedagógica de comunicación. No busca la verdad para entregarse a ella en un culto

\footnotetext{
${ }^{6}$ Ibid., p. 31.

7 Zambrano, M., Notas de un método, Madrid, Mondadori, 1989, p. 129.

${ }^{8}$ Zambrano, M., El pensamiento vivo de Séneca, op. cit., p. 27.

9 Zambrano, M., La vocación del maestro, Málaga, Ágora, 2007, p. 101.
} 
silencioso y cerrado, sino con ánimo de transmitirla, de revelarla a otros en palabras que encaminen a esa verdad. Así, el "decir" zambraniano se ofrece desde el primer momento como "mediador", entre la realidad y la forma de expresarlo, entre la realidad y la comunicación:

Lo que se publica es para algo, para que alguien, uno o muchos, al saberlo, vivan sabiéndolo, para que vivan de otro modo después de haberlo sabido; para librar a alguien de la cárcel de la mentira, o de las tinieblas del tedio, que es la mentira vital ${ }^{10}$.

Educar es enseñar a salir de sí para compartir sueños comunes de convivencia que se alejen de cualquier clase de individualismo: "Convivir quiere decir sentir y saber que nuestra vida, aun en su trayectoria personal, está abierta a los demás ni importa sean nuestros próximos o no" ${ }^{11}$. La educación ha de abandonar el lastre de toda contaminación, que es un fardo que se pega e impide la trascendencia.

\section{La mediación del maestro}

Resulta llamativo Que algunos De los filósofos de la Escuela de Madrid tengan entre sus reflexiones una atención especial a la necesidad de tener un modelo de conducta. Tanto García Morente "La vocación del magisterio", como Zubiri en "Filosofía del ejemplo", como Zambrano en "La fuerza del ejemplo" dedican artículos a la importancia de sentir la educación bajo la tensión estimulativa de la referencia ante alguien ${ }^{12}$.

María Zambrano reflexiona acerca de la importancia de un modelo de pensamiento y de un modelo de vida. Pues el maestro es un estímulo o un acicate que ilumina la vida ${ }^{13}$ y especialmente puede despertar en otro el ser, abrir la conciencia. Esto significa mediación, pues es aquel que reta, anima, despierta y abre el horizonte para que el alumno pueda caminar con sentido hacia una meta. No hay modelo ni maestro si no se tiene la intención de mejorar la vida de alguien. En su artículo La mediación del maestro propone una racionalidad creativa y mediadora, es decir, aquella que busca sugerir y no imponer, exponer y no decidir por el otro. Por eso

\footnotetext{
${ }_{10}$ Zambrano, M., Hacia un saber sobre el alma, op. cit., p. 12.

11 Zambrano, M., Persona y Democracia, op. cit., p. 16.

12 Casado, A. y Sánchez-Gey, J., Filósofos españoles en la Revista de Pedagogía (1922-1936), Tenerife, Idea, 2007.

13 Casado, A. y Sánchez-Gey, J., “Sobre la vocación de maestro”, Tendencias Pedagógicas 14, 2009, pp. $209-215$.
} 
el maestro intenta conducir, extraer del discípulo algo más, puesto que "la función mediadora... no es otra cosa que el ejercicio de esa su esencia trascendente" 14 .

Es decir, las acciones propias de un maestro es la de ser mediador entre lo que es y lo que sueña ser, entre el aquí y la promesa de un futuro mejor: "El maestro [...] es mediador... entre el saber y la ignorancia, entre la luz de la razón y la confusión $[\ldots]$ hasta llegar a ser una persona íntegramente" ${ }^{15}$. Y es mediador porque tiene que descender hasta el alumno, así dice García Morente si se pretende enseñar sin tener en cuenta al discípulo, entonces el maestro carece de sabiduría y le sobra arrogancia. Mediar es descender, abajarse a fin de hacerse comprender, de poder ilusionar, de encender en el otro la ilusión, no porque se enseñe menos sino porque se busca enseñar mejor. "Y así el maestro [...] ha de hacer descender, por así decir, sobre él razón, bien y verdad, también armonía y orden, fundamentos de la belleza en función justamente del ser; mediador ante todo y sobre todo de sí mismo" ${ }^{16}$.

La mediación supone ofrenda de sí para que el educando alcance una vida en plenitud, darse para que el discípulo se forme de manera íntegra, supone igualmente apertura a la trascendencia, pues todo acto educativo es un acto comunicativo, abierto y Zambrano subraya el deseo de no ponerle límites: "el maestro es mediador con respecto al ser en tanto crece, y crecer para lo humano es no sólo aumentar sino integrarse" 17 .

Es preciso que el maestro tenga autoridad moral, si no será un enseñante o, peor aún, un charlatán:

Porque el 'Maestro', antes que alguien que enseña algo, es un alguien ante el cual nos hemos sentido vivir en esa específica relación que no proviene tan sólo del valor intelectual. La acción del maestro trasciende el pensamiento y lo envuelve, sus silencios valen a veces tanto como sus palabras y lo que insinúa puede ser más eficaz de lo que expone a las claras ${ }^{18}$.

Esta autoridad moral proviene de su sabiduría y, especialmente, de su coherencia personal. Giner de Los Ríos pedía maestros, no medios materiales, ni locales, ni organizaciones.

Por ello el vínculo con el discípulo trasciende el contenido de lo que enseña, esto es lo formativo. Así, el contenido se convierte en verdadera ciencia que ayuda a saber y amplía el pensamiento. De este modo, la ciencia se torna sabiduría. Zambra-

\footnotetext{
${ }_{14}$ Zambrano, M., "La vocación de maestro. La mediación", en Casado, A. y Sánchez-Gey, J., Filosofía y Educación. Manuscritos, Málaga, Ágora, p. 113.

15 Ibid., p. 114.

16 Ibid.

17 Zambrano, M., "Escritos sobre Ortega, (ed. Ricardo Tejada), Madrid, Trotta, 2011, p. 87.

18 Ibid.
} 
no dice de Ortega: "[...] sus lecciones eran, en efecto, lecciones universitarias; pero algo en ellas rebosaba y trascendía de su carácter científico y rigurosamente objetivo, algo que parecía dirigirse, pasando por el estudiante, a la persona humana" ${ }^{19}$.

En efecto, sólo se llama maestro a quien despertó en el alumno sentimientos de singularidad, pues de algún modo le hizo sentir único y le trató con dignidad; pues el maestro es quien cuenta con la opinión del alumno, confía en él y, por tanto, aviva en su interior ilusión y reflexión. Esta implicación entre ambos se inicia en el entusiasmo del maestro que se entrega a la enseñanza con el desprendido deseo de ayudar a crecer al alumno: "Podría medirse quizás la autenticidad de un maestro por ese instante de silencio que precede a su palabra, por ese tenerse presente, por esa presentación de su persona antes de comenzar a darla en un modo activo. Y aun por el imperceptible temblor que la sacude. Sin ello, el maestro no llega a serlo por grande que sea su ciencia. Pues que ello anuncia el sacrificio, la entrega" 20 .

El acto educativo es una tarea personalizadora, la educación es propia de humanos entre humanos, porque sólo se realiza mediante la vivencia de una experiencia que se transmite con la palabra y con la vida. La educación contiene un fin: alcanzar a ser mejores, personal y colectivamente, pues al final sólo se recordará que el maestro fue aquel que nos hizo sentir bien. De ahí, que el entusiasmo sirva como elemento transmisor inmejorable, pues va unido a la emoción de la ofrenda a la idea. "No tener maestro es no tener ante quien preguntar y, más hondamente todavía, no tener ante quien preguntarse [...] La presencia del maestro que no ha dimitido - ni contradimitido- señala un punto, el único hacia el cual la atención se dispara. El alumno se yergue" 21 .

Para Zambrano el maestro es también guía, pues ejerce siempre de mediador en un sentido clarificador de la educación: la transformación para crecer y desarrollarse personalmente. Educar es educarse, es decir, cambiarse a fin de alcanzar mejores metas. El guía es aquel al que conviene escuchar, Zambrano prefiere la escucha más que la visión, pues la visión es una concepción más cercana al racionalismo griego. Así dice: "El hombre está siempre oyendo algo. En marcha sintiendo este algo más que viendo. Este algo que oye le guía" 22 . Educarse supone estar a la escucha de algo que nos adviene. La escucha pide ayuda, guía para seguir caminando, aquí se presenta la necesidad de un maestro.

\footnotetext{
19 Zambrano, M., "Escritos sobre Ortega, op. cit., p. 72.

${ }^{20}$ Zambrano, M., "La mediación del maestro" en Filosofía y Educación, Manuscritos, op. cit., p. 117.

21 Ibid.

22 M-340. Manuscritos ordenados por María Zambrano que están en la Fundación en Vélez-Málaga.
} 
La mediación es la actitud propia del guía pues su presencia evoca lo múltiple, lo universal y trascendente, pero al mismo tiempo, se acerca a lo concreto y lo esclarece: "El guía atraviesa las circunstancias y se aviene al par a ellas" ${ }^{23}$. Lo estimulante del guía es que conoce lo concreto pero lo trasciende, no impone pero orienta, estimula porque resulta ser un verdadero ejemplo.

Y es propio del guía no declarar su saber sino ejercerlo sin más. Enuncia, ordena, a veces tan sólo indica. No transmite una revelación... Su trascendencia viene tan sólo de su cumplimiento... un guía ofrece ante todo... una cierta música, un ritmo o una melodía que el guiado tiene que captar siguiéndola. De ahí que el que recibe un camino guía haya de salir de sí, del estado en que está, haya de despertar, siendo consciente ${ }^{24}$.

El maestro o guía es mediador porque ha sentido la vocación que, según Zambrano, es mucho más que profesionalización, porque no es sólo es tarea sino que el magisterio está cargado de misión. O dicho de otro modo, la profesión es un añadido a la actividad humana, mientras que la vocación conforma el vivir, puesto que es una forma de "responder al mundo". La vocación exige siempre dedicación, de ahí la importancia que Zambrano concede a la atención como una forma educadora de comportarse y estar en el mundo.

Finalmente, abordaremos, un aspecto importante respecto al sentido democrático de la educación en María Zambrano.

\section{El diálogo y la escucha}

ZAMBRANO ENTIENDE LA EDUCACIÓN como el diálogo activo entre maestro y discípulo y éste supone comunicación de ideas y de emociones, pues no basta con la sola razón. Por ello, es necesario que las personas puedan comunicarse a todos los niveles, en el plano más humano, o subjetivo, y también de forma integradora en todas las dimensiones y acciones humanas como es la ciencia, la religión o la política. De aquí se deriva la tolerancia, pues hay que respetar los derechos de cada uno, aunque sus ideas sean las antípodas de las propias.

Por ello, el maestro ha de ser cercano y contar con el discípulo e intentar dar sentido a lo que ya sabe y a lo que le queda por conocer. El acto educativo surge en la relación maestro-discípulo, en la necesidad de abrirse al diálogo, pues hay que estimular la creatividad, la curiosidad, la ilusión del alumno: "Y el maestro ha de

\footnotetext{
${ }^{23}$ Zambrano, M., "El guía” en Filosofía y Educación. Manuscritos, op. cit., p. 175.

24 Zambrano, M., Senderos, Barcelona, Anthropos,1986, p. 126.
} 
ser quien abra la posibilidad, la realidad de otro modo de vida, de la de verdad. Una conversión es lo más justo que sea llamada la acción del maestro. La inicial resistencia del que irrumpe en las aulas, se torna atención [...] Ignorancia y saber circulan y se despiertan igualmente por parte del maestro y del alumno, que sólo entonces comienza a ser discípulo. Nace el diálogo" 25 .

En el diálogo hay que llegar al corazón humano, hay que conocer las cualidades de cada discípulo y potenciarlas, sin embargo, la masificación no permite esta observación. Pues el diálogo está hecho de palabras y de silencios: "En el vacío del aula sucede algo; algo que va más allá de lo que se aprende materialmente en ellas. Muchos de los que por ellas han pasado tal vez no adquirieron tantos conocimientos como fuera menester. Pero les sucedió algo en la frecuentación de las aulas; algo esencial para ser hombre se les enseñó en ellas: a oír, a escuchar, a atender, a dejar que el tiempo pase sin darse cuenta queriendo entender algo, abrirse al pensamiento que busca la verdad" 26 .

Educar es saber escuchar el logos oculto, el sentir originario, la música callada que guía los pasos y complete la verdad que se busca. María Zambrano habla así del aula, como lugar de escucha y de silencios, como lugar en el que se aprende a madurar, es espacio de amor porque ha de gustar, porque parte de una verdadera elección, como un modo de vida que sirve a la convivencia y al aprendizaje. Refiriéndose a su padre dice: "Sabía escuchar como muy pocas gentes y había querido enseñarla a hacerlo desde nińa" ${ }^{27}$.

La razón mediadora se alcanza a base de silencios atentos para relacionarse bien los unos y los otros, a base de admiración a fin de prestar oídos a lo importante de la enseñanza. Para ello se requiere la educación de la atención, pues la conciencia humana tiene esta capacidad o atributo de alcanzar la claridad.

\footnotetext{
25 Zambrano, M., "La mediación del maestro", op. cit., p. 118.

26 Ibid., p. 173.

27 Zambrano, M., Delirio y destino, Madrid, Mondadori, 1989, p. 105.
} 


\section{REFERENCIAS BibLIOGRÁficas}

Casado, A. y Sánchez-Gey, J., Filósofos españoles en la Revista de Pedagogía (1922-1936), Tenerife, Idea, 2007.

Zambrano, M., Hacia un saber sobre el alma, Madrid, Alianza Editorial, 1987.

Zambrano, M., El pensamiento vivo de Séneca, Madrid, Alianza Editorial, 1987.

Zambrano, M., Persona y Democracia, Barcelona, Anthropos, 1992.

Zambrano, M., Senderos, Barcelona, Anthropos, 1986.

Zambrano, M., Notas de un método, Madrid, Mondadori, 1989.

Zambrano, M., Delirio y Destino, Madrid, Mondadori, 1989.

Zambrano, M., Filosofía y Educación, edición de Ángel Casado y Juana Sánchez-Gey, Málaga, Ágora, 2007.

Zambrano, M., Escritos sobre Ortega, edición de R. Tejada, Madrid, Trotta, 2011.

DOI: https://doi.org/10.15366/bp2020.25.003

Bajo Palabra. II Época. No25. Pgs: 65-76 
